\title{
Os Tentáculos da Tarântula: Abjeção e Necropolítica em Operações Policiais a Travestis no Brasil Pós-redemocratização
}

\author{
Céu Cavalcanti ${ }^{1}$ \\ ${ }^{1}$ Universidade Federal do Rio de Janeiro, RJ, Brasil \\ Roberta Brasilino Barbosa ${ }^{1}$ \\ ${ }^{1}$ Universidade Federal do Rio de Janeiro, RJ, Brasil \\ Pedro Paulo Gastalho Bicalho ${ }^{1}$ \\ ${ }^{1}$ Universidade Federal do Rio de Janeiro, RJ, Brasil
}

\begin{abstract}
Resumo: O artigo tem como proposta central analisar um conjunto de racionalidades que perpassam a configuração dos processos de incriminação-criminalização de travestis. Tomando como acontecimento-chave uma operação policial que teve início em 27 de fevereiro de 1987 na cidade de São Paulo - Operação Tarântula -, almejou-se compreender como a mesma surge enquanto condição de possibilidade de um contexto sociopolítico específico; mas que, para além dele, apontam-se pistas para um modus operandi que produz corpos travestis a partir de uma política da inimizade e da abjeção. Investiga-se linhas de força que compõem a materialidade da operação policial e os processos de subjetivação produzidos - e que se mantêm após mais de três décadas. A partir da análise de diferentes registros percebe-se que o acionamento de pânico moral direcionado a corpos travestis mobiliza circuitos de racionalidades capazes de agregar discursos sobre segurança pública em dinâmicas de seletividade penal advindas de composições necropolíticas. Entendendo as condições que possibilitam as relações entre o Estado penal e as pessoas travestis que ocorriam no momento de redemocratização do Brasil, podemos perceber rastros dos elementos que ainda hoje perpassam tais relações.
\end{abstract}

Palavras-chave: Travestis, Abjeção, Necropolítica, Segurança Pública.

\section{The Tarantula Tentacles: Abjection and Necropolitics in Police Operations to Trans Women in Post-redemocratized Brazil}

\begin{abstract}
The article has as a central proposal to analyze a set of rationalities that cross the configuration of the processes of incrimination-criminalization of trans women. Taking a police operation that began on February 27, 1987 in the city of São Paulo - Tarantula Operation - as a key event, the aim here is to understand how the so-called operation arises as a condition of possibility of a specific socio-political context; in addition to it, this article points to a modus operandi that understands trans women as bodies based on a politics of enmity and of abjection. Investigating whether such lines of force that make up the materiality of a police operation continue to produce effects 30 years later is also the purpose of this text. From the analysis of different records, we can see that the activation of moral panic directed to trans women bodies mobilizes circuits of rationalities capable of adding discourses on public security in dynamics of penal selectivity coming from necropolitcs compositions. Understanding the conditions that make possible the relations between the criminal state and the trans women that occurred at the moment of redemocratization of Brazil, we can perceive traces of the elements that still pervade these relations.
\end{abstract}

Keywords: Trans Women, Abjection, Necropolitics, Public Security. 


\section{Los Tentáculos de la Tarántula: Abyección y Necropolítica en}

\section{Operaciones Policiales a Travestis en Brasil Post-redemocratización}

Resumen: El artículo tiene como propuesta central analizar un conjunto de racionalidades que atraviesan la configuración de los procesos de incriminación-criminalización de travestis. Tomando como acontecimiento clave una operación policial que comenzó el 27 de febrero de 1987 en la ciudad de São Paulo - Operación Tarántula -, se anheló comprender cómo la misma surge como condición de posibilidad de un contexto sociopolítico específico; pero que, además de él, se apuntan pistas para un modus operandi que produce cuerpos travestis a partir de una política de la enemistad y de la abyección. Se investiga líneas de fuerza que componen la materialidad de la operación policial y los procesos de subjetivación producidos - y que se mantienen después de más de tres décadas. A partir del análisis de diferentes registros podemos percibir que el accionar de pánico moral dirigido a cuerpos travestis moviliza circuitos de racionalidades capaces de agregar discursos sobre seguridad pública en dinámicas de selectividad penal provenientes de composiciones necropolíticas. Entendiendo las condiciones que posibilitan las relaciones entre el Estado penal y las personas travestis que ocurrían en el momento de redemocratización de Brasil, podemos percibir rastros de los elementos que aún hoy atraviesan tales relaciones.

Palabras clave: Travestis, Abyección, Necropolítica, Seguridad Pública.

\section{Introdução: tecendo a linha}

A experiência travesti na população é mais patética que a mesma pobreza. Nos acampamentos, os meninos afeminados entendemos que merecemos a discriminação, a violência e o maltrato psicológico dos pobres. Pobres que são nossa própria família, pais e nossos irmãos, e também os professores, eles de quem se deve esperar proteção e educação, também deles recebemos desprezo ${ }^{1}$ (Cláudia Rodriguez, em: Las travestis debemos tener derecho a leer sobre lo que escriban outras travestis).

$\mathrm{O}$ artigo que se segue é organizado a partir de uma série de incômodos que atravessam algumas das constatações que aqui se tentam organizar. Analisar o lugar que historicamente as travestilidades vêm sendo alocadas em nossos contextos sociais abre um nicho no pensamento que convida a observar algumas brechas, como uma reflexão sobre fascismos cotidianos e suas materialidades que se enraízam em diferentes regimes de organização do Estado, marcados por um projeto de acirramento da violência direcionada a corpos trans. Em que pesem incontestáveis violências ocorridas no período ditatorial no Brasil, operações policiais ocorrem justamente no período de redemocratização e se mantém por vários anos após significativas mudanças sociais e políticas no Brasil, fato que nos alerta que a violência transfóbica é estabelecida como ação rotineira e cotidiana do Estado penal, operado por políticas de segurança pública.

Cláudia Rodriguez, no texto Las travestis debemos tener derecho a leer sobre lo que escriban outras travestis (goo.gl/ddgLqX, recuperado em 02 de julho, 2018), aponta o caráter transversal das violências transfóbicas ao comentar que há um regime de produção constante da violência que incute nas subjetividades travestis níveis de aceitação do lugar da subalternidade. Como se de algum modo passássemos a crer que os lugares de inferiorização socialmente impostos são os únicos que nos cabem no percurso da vida. Porém, ao conseguirmos nos desvincular minimamente dessas amarras, a composição de projetos que desprivatizem sofrimentos e apontem o caráter coletivo da violência se fazem urgentes. Cláudia ainda aponta que um dos efeitos mais perversos da dinâmica de sujeição é

\footnotetext{
${ }^{1}$ Livre tradução nossa do texto: “La experiencia travesti en la población es más patética que la misma pobreza. En los campamentos los niños afeminados entendemos que merecemos la discriminación, la violencia y el mal trato psicológico de los pobres. Pobres que son nuestra propia familia, padres y nuestros hermanos, y también los profesores, ellos de quienes se debe esperar protección y educación, también de ellos recibimos desprecio".
} 
a incapacidade de autodefesa, qual neste contexto é diretamente vinculada à capacidade de produção e compartilhamento de pensamento crítico, o que por sua vez, remete a acessos educacionais e apropriação de linguagens e ferramentas discursivas. Defender nosso direito a existir é necessariamente produzir registros sobre nossa história coletiva e sobre nuances de formas de pensamento que ao se organizarem no decorrer do tempo histórico possibilitam que hoje o Brasil seja apontado como país líder no ranking de assassinatos de pessoas trans.

Enquanto seguimos vivenciando formas radicais de exclusão, este texto pode inclusive ser lido como uma tentativa singela de autodefesa e como um convite a que possamos estar atentas aos registros que, somados, pouco a pouco naturalizam o absurdo.

Desde a minha perspectiva, ao ser estranhas, afeminadas, e por essas razões ao não aderirmos ao modelo de educação, não só se impediu que aprendêssemos a ler e escrever como fez que se produza a pior das violências da modernidade, uma violência grave dos direitos humanos. Me refiro a incapacidade de nos defender, de defender nosso direito a existir aqui nesse território, estranhas, feias, malfeitas, porém com a capacidade de fazer reflexões críticas a respeito de nosso próprio mundo. $\mathrm{O}$ mundo não crê que podemos ser inteligentes e capazes ${ }^{2}$ (goo.gl/ddgLqX, recuperado em 02 de julho, 2018).

O final dos anos 1980 é marcado pelo processo de redemocratização do país, momento em que aberturas políticas inflam ares de renovação nas coletividades após décadas de regime ditatorial (Bicalho, 2013). Marilena Chauí e Marco Aurélio Nogueira ao refletirem sobre esse tempo histórico pontuam que por ter se dado de forma gradual, é simplista eleger uma data fixa enquanto marco do momento de redemocratização. Os autores apontam os anos finais da década de 1980 como o momento em que o Estado brasileiro se reorganiza, mas lembram ainda que um projeto de redemocratização passa a ser algo contínuo, que a partir de diferentes perspectivas pode ter diferentes marcações, como a promulgação da Constituição Federal de 1988, ou a tentativa de estabilização econômica em 1994 ou ainda as eleições de 2002, quando pela primeira vez o país elege um operário como presidente (Chauí, \& Nogueira, 2007).

Independente do marco temporal que possamos optar, o estabelecimento de uma democracia perpassa a garantia de direitos fundamentais para as populações vulnerabilizadas e, de uma forma ampliada, a composição de grandes sistemas públicos, como o Sistema Único de Saúde (SUS) e o Sistema Único de Assistência Social (SUAS), e garantias legais, como o Estatuto da Criança e do Adolescente (ECA), partem dessa lógica e se inscrevem no plano de "abertura" política e social. No momento em que tais composições eram planejadas e efetivadas em todo o país, o lugar das travestilidades é algo que interessa observar.

Em uma publicação de 2016, Donna Haraway pensa sobre a noção de pensamento tentacular e, na construção teórica, ironicamente centraliza a imagem de um pequeno ser, uma aranha que existe somente na região de sua residência. Haraway recorre à imagem da Pimoa chthulu apontando que esta, ainda que pequena, possui grandes tentáculos. "Tentacularidade é sobre vida vivida ao longo de linhas"3 (Haraway, 2016, p. 2) - ela completa, para em seguida afirmar a necessidade de uma forma de pensamento que considere as diferentes linhas de poder que operam simultaneamente em diferentes direções e com diferentes efeitos práticos.

Não é objetivo desse artigo aprofundar o pensamento de Donna Haraway, tampouco operacionalizar a concepção de antropoceno (chave para o tipo de tentacularidades apontadas pela autora), mas interessa buscar a metáfora das redes, das aranhas e dos tentáculos para iniciar esse texto problematizando a confluência de linhas de poder marcadas em tempos e espaços muito específicos. Aqui também se faz necessário evocar uma imagem que surge contextualizada, mas que ainda hoje operacionaliza racionalidades e ações. A aranha que habita esse texto é a tarântula e sua imagem surge no imaginário criminal brasileiro

\footnotetext{
${ }^{2}$ Livre tradução nossa do texto: "Desde mi perspectiva, el ser raras, afeminadas, y por estas razones al no adherirnos al modelo de educación, no solo impidió que aprendiéramos a leer y escribir, sino que se produzca la peor de las violencias de la modernidad, una violencia grabe de los derechos humanos, me refiero a la incapacidad de defendernos, de defender nuestro derecho a existir aquí, en este territorio, raras, feas, maltrechas, pero con la capacidad de hacer reflexiones críticas respecto de nuestro propio mundo. El mundo no cree que podemos ser inteligentes y capaces" (Rodriguez, 2016).

${ }^{3}$ Livre tradução nossa do texto: “Tentacularity is about life lived along lines".
} 
entre fevereiro e março de 1987 quando uma grande operação policial em São Paulo ganha o nome de "Operação Tarântula".

Uma nota na Folha de São Paulo publicada no dia $1^{\circ}$ de março de 1987 chama a atenção por ser um tímido apontamento da época marcando a existência de uma operação planejada diretamente para travestis (Figura). A construção narrativa da matéria por si já é algo que, sob análise, nos revela a composição de uma racionalidade que interessa a esse texto observar. Por racionalidade entendemos junto ao pensamento de Foucault que há uma relação entre razão e poder na organização das práticas e, desse modo, observa-se a história que permeia os dispositivos e que nos permite apreender certo sentido instrumental nos discursos: "Organizar os meios para alcançar um fim" (Castro, 2009, p. 375).

O objetivo aqui almejado, portanto é, entender como a denominada Operação Tarântula surge enquanto condição de possibilidade de um contexto sociopolítico específico mas que, para além dele, aponta pistas para um modus operandi que entende os corpos travestis a partir de uma política da inimizade (Mbembe, 2016) e da abjeção (Kristeva, 1989). Investigar o modo pelo qual as linhas de força que compõem a materialidade de uma operação policial seguem produzindo efeitos, mais de três décadas depois, também é objetivo desse texto.

\section{Entre o apocalipse e a Saúde Pública - A operação como resposta policial}

A matéria publicada no caderno Cidades em primeiro de março de 1987 (Figura) já chama a atenção por seu título sensacionalista forjado em uma lógica que, se nos parece estranha, é por si capaz de apontar uma forma de construção do pensamento que integra polícia civil, $\operatorname{AIDS}^{4}$ e travestis. Pontua que o delegado-chefe do departamento das delegacias regionais de polícia da grande São Paulo (Degran), em entrevista para a Folha comenta que "Os tempos de Nostradamus estão chegando” (Polícia Civil..., 1987). Tal afirmação encontraria respaldo nos então recentes debates sobre a proliferação do HIV e no imaginário coletivo presente nos anos 1980 e parte dos anos 1990 da "peste gay".

Associado a um pensamento de cunho religioso apocalíptico, a criminalização ${ }^{5}$ da prostituição aparece como elemento central somado ao foco exclusivo nos corpos trans. Esse nó pode ser entendido quando analisamos as linhas da história que atravessam a composição deste acontecimento.

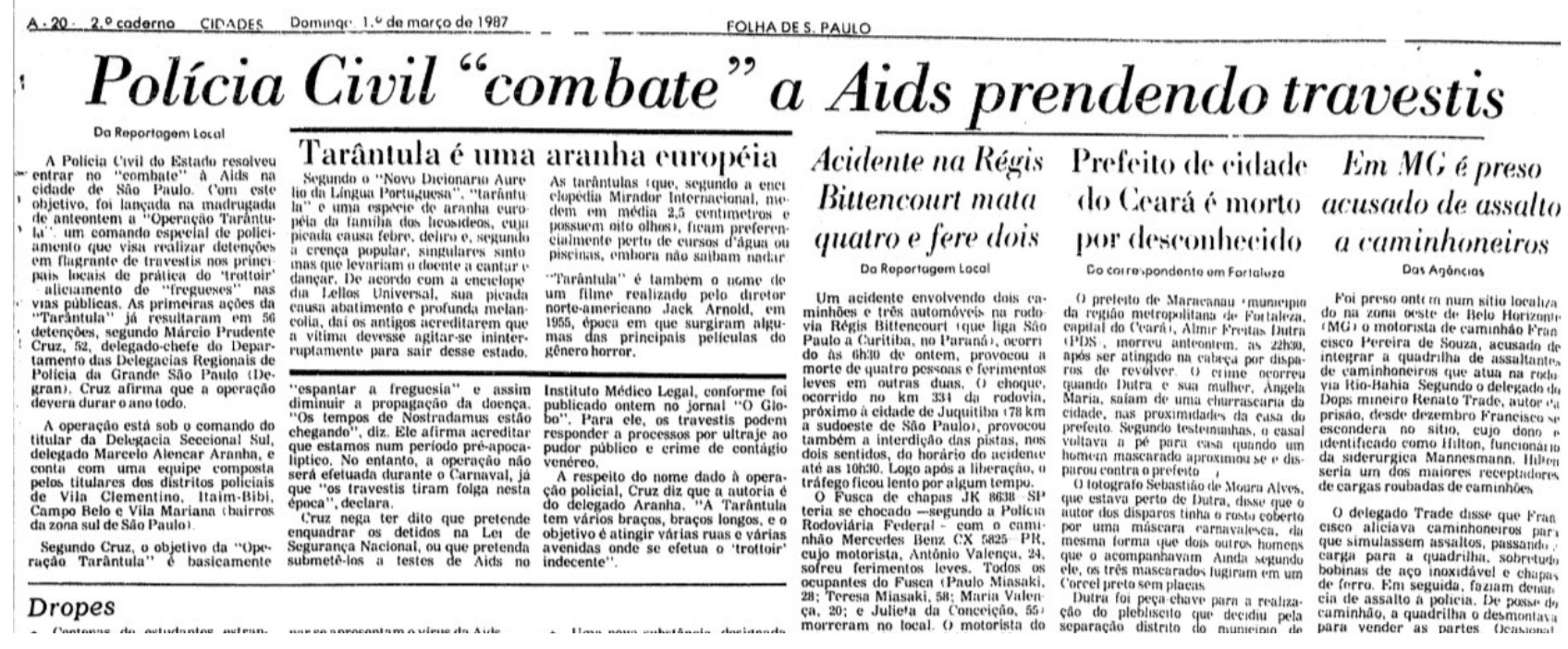

Figura

Folha de São Paulo, $1^{\circ}$ de março, 1987.

\footnotetext{
${ }^{4}$ Não aprofundaremos durante o texto conceituações históricas sobre as terminologias adotadas pela mídia e pelos discursos epidemiológicos para falar sobre AIDS, contudo no decorrer da escrita utilizaremos os termos AIDS e HIV.

${ }^{5}$ Chamamos atenção aqui para a distinção entre criminalização e incriminação melhor trabalhada mais adiante. Por criminalização podemos entender os processos que visam associar o ato transgressão a determinado sujeito enquanto a incriminação partiria de uma dinâmica de construção de argumentações legais já dentro de uma dinâmica penal (Misse, 1999).
} 
Os discursos sobre a AIDS operam como legitimadores de uma série de violações e têm a função de demarcar inimigos a serem combatidos. No contexto brasileiro, a grande mídia passa a explanar o tema exatamente no momento da redemocratização e paradoxalmente cria-se um discurso coletivo que observa seletivamente os casos recém-descobertos, mantendo o foco nas pessoas LGBT e invisibilizando casos de contaminação entre heterossexuais cisgêneros (Barata, 2006). Pensando sobre uma cronologia da epidemia de HIV/AIDS no Brasil entre 1980 a 2001, Galvão (2002) traz alguns marcos que nos ajudam a observar como uma linearidade paralela aos processos democráticos foi se compondo e surgindo como questão para as políticas públicas e para a sociedade brasileira em geral. Algumas datas que podem ser destacadas nesse contexto são:

* 1980 - O Boletim Epidemiológico notifica [a posteriori ${ }^{6}$ o primeiro caso de AIDS no Brasil.

* 1981 - O Jornal do Brasil publica uma primeira matéria sobre o tema com o título "Câncer em homossexuais é pesquisado nos EUA".

* 1983 -A mídia noticia os "primeiros casos de AIDS no Brasil". No mesmo ano morre em Nova Iorque Marcos Vinicius Resende Gonçalves, o Markito. Sendo ele um estilista reconhecido na época, as notícias de sua morte reforçavam a interpretação de que os primeiros casos no Brasil eram de homens gays de classe média que tinham contato com o exterior.

* 1984 - o boletim epidemiológico registra para este ano 140 casos e 105 mortes.

* 1985 - O Ministério da Saúde publica a Portaria $n^{\circ} 236$ que estabelece diretrizes para o programa de controle da AIDS. Nesse mesmo ano o boletim epidemiológico registra 573 casos e 462 óbitos; Fundação em São Paulo da primeira casa de apoio para pessoas vivendo com HIV/AIDS, organizada por Brenda Lee, travesti que transforma o lugar onde recebia clientes, "Palácio das princesas", em casa de apoio para pessoas que não tinham suporte algum ao ficarem doentes, sobretudo travestis e gays pobres.

* 1986-Criação da comissão de Assessoramento em AIDS, depois renomeada para Comissão Nacional de AIDS (CNAIDS); Fundação no Rio de Janeiro da Associação Brasileira Interdisciplinar de AIDS (ABIA); publicação da Portaria do Ministério da Saúde no 542/1986 que estabelece a notificação compulsória de casos de AIDS.

* 1988 - Criação do programa nacional de AIDS; Início da distribuição de medicamentos pelo sistema público de Saúde; Criação do SUS na nova constituição; Criação do Centro de Orientação e Apoio Sorológico (COAS), atual Centro de Testagem e Aconselhamento (CTA). O boletim epidemiológico reporta 4.585 casos de AIDS e 3.630 óbitos nesse ano.

Esse recorte de percurso cronológico ajuda a observar uma crescente notificação dos casos ao mesmo tempo em que o Estado brasileiro passa a observar mais atentamente a organização e as respostas possíveis a uma comorbidade então ainda desconhecida. Terto Júnior (2002) cita que na primeira década da epidemia, a associação da AIDS com homens gays e mulheres trans era tão naturalizada que ela era comumente nomeada nos debates acadêmicos de Gay Related Immunedeficiency (GRID) enquanto na mídia e consequentemente na opinião pública era denominada câncer gay, peste gay ou peste rosa.

Enquanto a saúde ao mesmo tempo em que ia se compondo como Sistema Único era convocada a responder à epidemia de AIDS, outros setores da sociedade se sentiram chamados a, por sua vez, pensarem respostas pragmáticas. A polícia, como aponta a matéria da Folha de São Paulo, foi um destes. Numa resposta que não passa por um debate da epidemiologia, o atual Código Penal Brasileiro (promulgado em 1940) ganha uma nova funcionalidade a partir do Artigo 130 que cita:

Art. 130 - Expor alguém, por meio de relações sexuais ou qualquer ato libidinoso, a contágio de moléstia venérea, de que sabe ou deve saber que está contaminado:

Pena - detenção, de três meses a um ano, ou multa.

$\S 1^{0}$ - Se é intenção do agente transmitir a moléstia: Pena - reclusão, de um a quatro anos, e multa (Decreto-Lei No 2.848, 1940)

${ }^{6}$ Jane Galvão aponta que o boletim epidemiológico sobre a AIDS começa a circular em 1987, contudo há nas primeiras edições uma tentativa de resgatar registros de notificações dos anos anteriores ao próprio boletim. 
Esse artigo é suficiente para justificar a existência da Operação Tarântula, uma vez que as travestis apreendidas deveriam, segundo o delegado Márcio Prudente Cruz, responder a processos por crime de contágio venéreo. Não à toa, a matéria cita rapidamente a possibilidade de existência de testagem compulsória das pessoas detidas para averiguação, fato que Márcio Cruz nega acontecer. Contudo, a naturalidade com que a dinâmica de associar travestis a AIDS e, consequentemente, o enquadramento no artigo 130 do Código Penal falam de como o imaginário de uma "epidemia gay" aciona uma interpretação sobre o sistema penal que faz décadas já operacionalizava a interface da vivência da negritude com a justiça (Goés, 2015). Trata-se aqui da diferenciação - ainda que não explícita - entre um direito penal do fato e de um direito penal do autor.

Noções que naturalizam a proposição de que determinados sujeitos são mais propensos ao delito que outros encontram raízes na criminologia positivista $^{7}$. Luciano Goés (2015) investiga a relação entre teoria proposta por Césare Lombroso e estratégias de aplicação desta no contexto brasileiro articuladas por Nina Rodrigues. Partindo de pressupostos de um pensamento evolucionista que divide as pessoas a partir de diferentes lugares numa suposta escala evolutiva, o ápice de perfeição e civilização, sendo modelo para todos os outros povos, seria justamente o homem, branco, europeu, cristão, heterossexual, cisgênero. A partir deste e de seus modos de vida, medem-se todas as outras pessoas, numa ficção epistemológica que justifica ações como o colonialismo, massacres e genocídios (Goés, 2015).

Ainda para Luciano Goés (2015), a eleição da delinquência lombrosiana como conceito central do direito penal positivista, propicia duas formas distintas de entender o delito a partir da separação entre criminoso de ocasião e criminoso "nato". Ao criminoso "de ocasião", as leis comuns tal como já eram postuladas eram suficientes para Lombroso, mas sua preocupação era com aquelas pessoas que, por não atingirem o mesmo nível evolutivo do homem branco europeu, não seriam capazes de reflexão moral mínima e, por- tanto, estariam sempre sujeitos a cometer atrocidades impulsivamente. No contexto brasileiro, Nina Rodrigues teve papel-chave na adaptação da criminologia positivista aos nossos contextos coloniais e escravocratas. Ao publicar em 1899 o texto Mestiçagem, degenerescência e crime, Nina propõe explicitamente o lugar da delinquência para pessoas que até poucos anos antes eram escravizadas e seus descendentes, posto que sua "selvageria", sem o controle dos senhores de escravos, causariam um aumento substancial nos crimes. Segundo o próprio Nina:

A facilidade com que a impulsividade selvagem se transforma em manifestações mórbidas de cólera entre as raças inferiores supostamente civilizadas e entre os mestiços, tomando uma forma obviamente epileptóide, mostra o alto grau de desequilíbrio no qual eles vivem e as condições precárias de sua adaptação à vida civilizada (Rodrigues, 1899, p. 41).

Uma racionalidade como essa se enraíza nas práticas cotidianas e produz efeitos subjacentes. No contexto em que o Estado brasileiro investe em processos de branqueamento da população, na medida em que se cria o lugar social da degenerescência para pessoas não brancas, abre-se um sistema de pensamento que interpreta o delito a partir de uma relação direta com os marcadores sociais de quem o comete. O próprio Nina chega a propor uma separação necessária no código penal onde, dado o caráter selvagem da população negra, haveria uma necessidade de distinção entre os crimes cometidos pela suposta incapacidade de empatia e reflexão e entre os crimes "de ocasião" cometidos por pessoas brancas que "ocasionalmente" erravam.

Resgatar brevemente a história das propostas de distinção do direito penal para o fato e para o autor, nos ajuda a voltar à Operação Tarântula para perceber que operava uma lógica muito similar, em que não haveria sequer a necessidade de comprovar a existência de algum delito por parte das travestis detidas, pois justo pelo fato de serem travestis é certo que se não ocorreu o delito foi apenas por falta de possibi-

\footnotetext{
${ }^{7}$ A criminologia positivista pode ser entendida como uma escola do pensamento criminológico atravessada pelo pensamento da filosofia positivista. Desse modo, elementos como busca pela cientificidade e uso de métodos experimentais universalizantes (como a frenologia) emprestam à criminologia pontes de ligação entre direito penal e o pensamento evolucionista. Um dos principais expoentes dessa escola é Césare Lombroso e o conceito de delinquência pode ser entendido como chave do modo de pensamento que liga a transgressão a determinados sujeitos, buscando em explicações que unem biologia e moral, as explicações para os delitos. Têm-se aqui uma função de ordenamento hierarquizado das estruturas sociais (Elbert, 2003).
} 
lidade e este, certamente, ocorrerá. Para as travestis, assim como para a população negra, é acionado o direito penal do autor. A punição, dentro dessa racionalidade, decorre de quem se é, não necessariamente do que se fez.

\section{Abjeção, pânico moral e direito penal}

O pensamento europeu sempre tendeu a abordar a identidade não em termos de pertencimento mútuo (copertencimento) a um mesmo mundo, mas antes na relação do mesmo com o mesmo, do surgimento do ser e da sua manifestação em seu ser primeiro ou, ainda, em seu próprio espelho (Mbembe, 2014, p. 10).

Com esse trecho do primeiro capítulo do livro Crítica da razão negra, Achile Mbembe traça uma linha que aponta como o pensamento europeu centra a si mesmo enquanto universalização à medida que passa a constantemente necessitar definir para si próprio suas fronteiras. Ao pensar a identidade como um processo de autoficção autocontemplativa (Mbembe, 2014) a exclusão radical do não eu torna-se fundamento da própria autoafirmação europeia. Nessa dinâmica, operam formas de produção de subjetividade que ao centralizar o eu europeu (com seu modo de vida, crenças, cultura e valores) define um modelo de humanidade que já em sua origem não comporta todas as pessoas.

A eleição das fronteiras como premissa da produção de si pressupõe que a diferença seja vista não como pertencimento mútuo, mas como uma exterioridade que inclusive é tida como ameaça. A diferença sustentada por corpos travestis e por corpos negros parecem então demarcar um lugar que historicamente não é o de humano. Esse lugar, oriundo de um sistema de pensamento produzido e imposto pela Europa, pode inclusive ser pensado como um não lugar e a ojeriza que esta diferença muitas vezes causa pode ser analisada a partir da noção de abjeção. O que justifica que o direito penal do autor seja em determinado momento proposto e acionado para pessoas negras e o que embasa a prisão arbitrária de travestis pela Operação Tarântula fazem parte da mesma racionalidade, e aqui Julia Kristeva nos ajuda a pensar:

Há, na abjeção, uma dessas violentas e obscuras revoltas do ser contra aquilo que o ameaça e que lhe parece vir de um fora ou de um dentro exorbitante, jogado ao lado do possível, do tolerável, do pensável. Está lá, bem perto, mas inassimilável. Isso solicita, inquieta, fascina o desejo que, no entanto, não se deixa seduzir. Assustado, ele se desvia. Enojado, ele rejeita. Um absoluto o protege do opróbrio, com orgulho a ele se fia e o guarda. Mas, ao mesmo tempo, mesmo assim, esse elã, esse espasmo, esse salto é lançado em direção de um outro lugar tão tentador quanto condenado. Incansavelmente, como um bumerangue indomável, um polo de atração e de repulsão coloca aquele no qual habita literalmente fora de $\mathrm{si}^{8}$ (Kristeva, 1989 p.7).

No texto Os poderes da perversão, Julia Kristeva discute sobre como um fora radical sempre possibilita o traçado cultural do que será considerado normal e desejado. Na metáfora linguística psicanalítica que a autora utiliza em sua teorização, o ab-jeto seria como um lugar, uma relação de interdito que sob hipótese alguma pode ser acionada como possibilidade, pois sua não existência é justamente o que regra as fronteiras da humanidade. Contudo, é um lugar que apesar de impossível desde sempre, precisa existir em um estranho paradoxo no qual o desejo (o sujeito, o humano) se vê marcado por uma ambivalência de interesse e repulsa, ao mesmo tempo.

Kristeva não dialoga em sua obra com o pensamento descolonial mas, se refletimos sobre o conceito de abjeção em paralelo ao apontamento da organização do pensamento europeu proposto por Mbembe, podemos pensar aqui em cruzamentos possíveis, para propor que o processo nomeado como abjeção é em si decorrente de um manejo imperialista da produção do sujeito europeu. Uma vez que este precisou em momentos de expansão de

\footnotetext{
${ }^{8}$ Livre tradução nossa do texto: "Hay en la abyección una de esas violentas y oscuras rebeliones del ser contra aquello que lo amenaza y que le parece venir de un afuera o de un adentro exorbitante, arrojado al lado de lo posible y de lo tolerable, de lo pensable. Alli esta, muy cerca, pero inasimilable. Eso solicita, inquieta, fascina el deseo que sin embargo no se deja seducir. Asustado, se aparta. Repugnado, rechaza, un absoluto lo protege del oprobio, esta orgulloso de ello y lo mantiene. Y no obstante, al mismo tiempo, este arrebato, este espasmo, este salto es atraído hacia otra parte tan tentadora como condenada Incansablemente, como un búmerang indomable, un polo de atracción y de repulsión coloca a aquel que esta habitado por él literalmente fuera de sî".
} 
si lidar com as diferenças, a resposta afirmada foi a colonização, a escravização e o genocídio - em suma, a aniquilação do outro. Algo que não chega a ser um alguém, pois não é composto como ob-jeto de reconhecimento, é forjado como não lugar, como constante oposição na divisão maniqueísta das eternas batalhas cristãs. No mundo da expansão imperialista, não cabem modos de copertencimento.

O inferno são os outros, negros, indígenas, silvícolas, adoradores de deuses pagãos, primitivos, incivilizados, bárbaros, animalescos, desalmados, em suma, desumanos. Em uma perspectiva de mundo aonde se compreende a contínua batalha da luz versus a escuridão, para esse modelo de pensamento só há um caminho, o extermínio. Devemos considerar que o extermínio, aqui entendido, opera de diferentes maneiras desde os genocídios, os epistemicídios, até as mais variadas formas de subalternização que incidem de forma violenta transformando "os ditos outros" em não possibilidades credíveis (Santos, 2008 como citado em Rufino, 2015, p. 3).

Se o inferno são os outros, como aponta Luiz Rufino, como bons cristãos defensores do bem é preciso se opor ao mal e ao inferno. A relação com a alteridade marcada pelos tons da abjeção elabora constantes desumanizações nas quais o encarceramento, o controle constante e o extermínio se justificam por relações dadas a priori. Podemos perceber os argumentos de desumanização, apontamentos de selvageria e demarcação do outro como perigo iminente que apresenta ameaça constante nas palavras do próprio Nina Rodrigues ao se referir sobre a população negra brasileira. Desumanização similar pode ser percebida ainda hoje incidindo sobre os corpos trans.

Alice Guél, rapper negra e travesti, lançou em 2017 um álbum intitulado Alice no país que mais mata travestis e na primeira faixa, As coisas vão mudar, ela elabora propostas de resistência enquanto num determinado momento da composição traz ao fundo trechos de entrevistas sensacionalistas com travestis na delegacia. Uma das falas aponta para a discussão que aqui se tenta fazer conceitualmente.

[...] que a gente somos ser humano também. Tem pessoas que não querem nem tocar na gente! Como se tivesse nojo da gente, nojo. O pessoal, a sociedade, queria muito que quando vissem a gente tratassem como uma pessoa normal (Guel, 2017).

Nesse trecho de fala, que é só mais um entre vários que intercalam as rimas de Alice, aparece com nitidez elementos que podemos definir como resultantes de abjeção. Um nojo, repulsa que não necessariamente decorre de argumentações lógicas, mas provém do regime de delimitação do outro. $\mathrm{O}$ nojo que o corpo travesti provoca ativa processos de desumanização e imposição de um lugar da monstruosidade que justificam o título que politicamente Alice usa em seu álbum - ela e nós vivemos no país que mais mata travestis.

Cabe aqui pensar se há uma relação entre abjeção e a proposição de um direito penal do autor enquanto forma de controle e apagamento constante do outro. Como lógica a sustentar a diferença de tratamento se faz necessária a noção de inimigo para criar uma realidade dual e fatídica, em que o extermínio é justificado pela máxima disjuntiva "ou eles ou nós". No contexto que possibilita a Operação Tarântula, os registros dos casos de HIV tiveram lugar chave na configuração das relações de inimizade (Mbembe, 2016) entre de um lado o Estado e a população em geral, e do outro as travestis e demais pessoas assumidamente LGBTI.

Rubin (2003), no texto Pensando o sexo: notas para uma teoria radical da política da sexualidade, aponta que a sexualidade deveria ter uma atenção especial em tempos de forte tensão política, pois este seria um dos campos onde os limites entre a moral, a religião e o Estado se borram. A autora faz um levantamento histórico e elege algumas intervenções significativas que muitas vezes decorrem do pânico social instalado pela produção discursiva sobre determinado grupo ou prática e que, valendo-se do medo coletivo, justifica as mais variadas respostas. Como exemplo, ela aponta como as campanhas vitorianas contra o que fora chamado de "escravidão branca" criaram um pânico coletivo que levou parte da população da Inglaterra a protestar pela alteração do Código Penal em 1885, criando cláusulas que previam mais permissividade na abordagem policial direcionada a mulheres pobres, ao mesmo tempo em que previu a punição de práticas sexuais tidas como desviantes. Como decorrência, a perseguição legal de prostitutas e LGBTIs passou a ter respaldo penal, contexto que só foi novamente alterado em 1967, 82 anos depois (Rubin, 2003). 
O manejo do pânico moral tem, portanto, finalidades políticas muito precisas (Reishoffer, \& Bicalho, 2009) sendo direcionado às populações minoritárias como um elemento de base do movimento de recrudescimento das cenas coletivas. No Brasil dos anos 1980, dados sobre a AIDS foram disparadores do pânico moral que mais uma vez apontou como culpadas determinadas minorias. A Operação Tarântula como resposta policial se inscreve então nesse contexto político. Cabe, porém, analisar que a operação foi apenas uma das respostas institucionais circunscrita num circuito de atos e efeitos com ramificações mais amplas e igualmente perversas. Como afirmado na entrevista para a Folha de São Paulo com o delegado responsável por nomear a operação: a tarântula tem de fato longos braços.

\section{Temporada de caça - a polícia, os outros e as pessoas de bem}

Centro de São Paulo no fim dos anos 1980. Uma repórter aborda uma mulher que caminhava tranquila e inicia o diálogo:

Repórter - Dá aqui uma entrevista pra gente. [a mulher para e assente com a cabeça] Repórter - Você tem ouvido falar nos noticiários, nos jornais, sobre assassinato de homossexuais? Mulher - Tenho sim.

Repórter - E o que você pensa disso?

Mulher - Eu acho que tem mais que assassinar mesmo.

[corta a cena e em seguida a repórter entrevista um adolescente sentado numa praça]

Repórter - O que você acha dessa onda de violência contra eles [LGBT]

Adolescente - Eu acho certo.

Repórter - Por quê?

Adolescente - Porque o homem nasceu pra ser homem, aí ficar virando... não dá não.

[a repórter agora para um motorista]

Repórter - E contra eles [LGBT] o que você tem contra eles?

Motorista - Ah, eu tenho muita coisa contra eles, eu acho que eles estão poluindo a cidade de São Paulo.

[...]

Repórter -Você acha que deveriam matar travestis?
Homem jovem - Bom, eu acho que se a lei permitisse, seria uma boa.

(Moreira, 1988).

Com essas entrevistas de pessoas comuns em um dia banal na cidade de São Paulo, Rita Moreira inicia o documentário Temporada de Caça (Moreira, 1988), filmado entre 1987 e 1988 e lançado em 1988, exatamente no momento em que ocorria a Operação Tarântula. Com essas falas, o documentário inicia uma série de explanações sobre a violência direcionada à população LGBTI de São Paulo e do Rio de Janeiro e aponta como acontecimento motivador o assassinato brutal ${ }^{9}$ do diretor de teatro Luís Antônio Martinez Correa, irmão do também diretor Zé Celso. A impunidade do crime de cunho visivelmente "lgbtifóbico" ocorrido em 1987 mobiliza pessoas vinculadas às artes e à dramaturgia, que fazem uma série de protestos públicos e denúncias, podendo o trabalho de Rita Moreira ser entendido como circunscrito nesse contexto.

Ao comentar sobre o que parece ser uma certa permissividade das instituições do estado que pode ser naquele contexto confundida com cumplicidade, Jorge Mautner comenta em entrevista a Rita no documentário que: "Já é a execução programática desses assassinatos de terror que acho que só farão aumentar em nível, quantidade e qualidade, sendo que brevemente eu posso estar na lista" (Moreira, 1988).

Em entrevista ainda no mesmo documentário, o jurista Hélio Bicudo diagnostica que o ódio direcionado à população LGBTI é cotidianamente fomentado pela mídia. Podemos pensar aqui, portanto, em uma relação direta entre produção de ódio, autorização coletiva de extermínio e garantia de impunidade. Esses três elementos se inscrevem num modelo de pensamento pautado inteiramente na inimizade como ordenador das relações estabelecidas com determinado grupo. Cabe atentar para o lugar do sistema penal na dinâmica em que, em nome da segurança cria atuações frente aos considerados "inimigos".

Embora não exista uma legislação claramente dirigida ao extermínio massivo no contexto contemporâneo, o sistema acaba operando em torno de uma seletividade brutal quando deslocado da generalização da criminalização primária para a

\footnotetext{
${ }^{9}$ Morto com mais de cem facadas em 23 de dezembro de 1987, o corpo de Luis foi encontrado em seu apartamento em Ipanema apresentando sinais claros de tortura. Uma matéria mais completa sobre o assassinato pode ser lida em Salvadori (2014).
} 
secundária: o programa legislativo "igualitário" é facilmente transformado em prática de perseguição ao inimigo, o que certamente diz algo sobre suas condições de possibilidades (Khaled Junior, 2016, p. 48-49).

Khaled Junior nos ajuda a entender como o discurso de ódio enquanto operador político aciona um determinado modo de funcionamento dos programas legislativos que se converte em prática de perseguição ao inimigo. Como elemento central está a passagem do que o autor entende como criminalização primária para a criminalização secundária ${ }^{10} \mathrm{de}$ forma seletiva e arbitrária. Na mesma direção, Misse (1999) pontua sobre a construção do crime no Brasil e a partir de uma leitura da proposta foucaultiana escreve sobre como os sistemas penais podem ter o foco ora na transgressão em si, hora no sujeito da transgressão. Essa mudança de perspectiva, como já anteriormente assinalada nesse texto produz formas diferentes de entender o ato e o objeto da transgressão e, para Michel Misse, aponta uma passagem da lei à norma. Essa mudança diria sobre o objeto da justiça em que os motivos da punição deixam de ser a garantia da lei enquanto instrumento coletivizado e passa a ser processos de imposição de uma determinada norma, punindo legalmente o que nas suas fronteiras não cabe (Misse, 1999). A relação entre incriminação e criminalização, entendida por Misse a partir da teoria foucaultiana, fala de um duplo movimento em que há a passagem da lei à norma para, em seguida, se afirmar um retorno da norma à lei, ou vice-versa; e, ainda que sob a égide da norma, produzindo com isso uma ambivalência que hora tem o foco no ato, porém, ao mesmo tempo, sempre considerando o autor da transgressão. O processo de criminalização se esforça, segundo Misse, por um contexto em que a acusação passa a propor relações diretas entre a transgressão e o sujeito transgressor. A incriminação seguiria aqui um trajeto racional-legal no qual, dentro de uma dinâmica acusatorial pautada na impessoalidade do procedimento legal, ocorre a construção da verdade da acusação. Contudo, Misse relembra a ambiguidade que perpassa as relações de incriminação-criminalização e comenta que se o que rege o processo for a norma, cria-se uma permissividade para que os agen- tes da incriminação negociem as acusações e seus efeitos, inserindo nos próprios processos de incriminação elementos que partem de percepções normalizantes (Misse, 1999).

Diante do contexto de produção do discurso de ódio, o acirramento de lógicas punitivistas direcionadas a grupos específicos aponta para processos de criminalização fundamentados em relações de acusação social complexas. Enquanto a manipulação do pânico moral dirige o ódio a algumas minorias, abre-se espaço para a culpabilização arbitrária de algumas pessoas que são responsabilizadas pelo acirramento das tensões sociais. Nessa direção a Operação Tarântula pode ser vista como um exemplo nítido de como processos de incriminação podem operar pela norma (e não somente pela lei), contaminando o processo penal com percepções coletivas pautadas na dinâmica de abjeção. Podemos, junto a Khaled Junior (2013), enxergar como processos penais podem se afastar do sistema acusatório, elemento básico do Estado democrático, e compor o processo como inquisitorial. A distinção entre um sistema acusatório e inquisitorial versa sobre o modo como a verdade é construída durante o processo penal. O modelo acusatório seria produto das sociedades democráticas e entende que a verdade penal é construída através de jogos discursivos entre acusação e defesa onde as instâncias que julgam observariam de fora para então proferir veredictos. No modelo inquisitorial vemos uma confusão entre as fronteiras dessas instâncias, onde quem juga é ao mesmo tempo quem acusa, de modo que a verdade produzida na acusação já é automaticamente julgada como procedente e o processo de julgamento toma o caráter de incutir provas a uma sentença já dada a priori (Khaled Junior, 2013).

A verdade e o ódio se entranham na Operação Tarântula, fazendo com que impere o caráter inquisitorial do modelo penal, na medida em que para serem enquadradas no artigo de crime de contágio venéreo, não importa aos operadores da lei sequer saber previamente se há contágio doloso ou mesmo se há alguma travesti contaminada. Não caberia ali uma dinâmica acusatória com direitos a defesa e argumentações como elementos centrais. A verdade seria construída pelos próprios agentes de incriminação, visando como único caminho responder hipóteses já

\footnotetext{
${ }^{10}$ Certas escolas da criminologia operam a partir das definições de criminologia primária e secundária, contudo, trabalhamos aqui a partir do pensamento de Foucault e de autores que nele se inspiram que conceituam esses fenômenos enquanto incriminação e criminalização.
} 
há muito formuladas. A linearidade da racionalidade assusta por ter sido operacionalizada em sua simplicidade. A fórmula travestis-são-perigosas-e-portanto-precisam-ser-encarceradas-em-massa atravessa barreiras geopolíticas e pode facilmente ser vista em vários outros estados que não chegaram a nomear operações de abordagem específicas para travestis, tampouco as publicitar.

Marta Sá, em uma entrevista para A Tarde TV, canal de notícias de Salvador comenta sobre a repressão vivenciada nos anos 1970 e 1980 e fala da arbitrariedade das abordagens policiais.

E quando eles faziam aquela arbitrariedade com a gente eles diziam: isso é pelo nome dos bons costumes, que raspavam a cabeça da gente, batiam. Se viam a gente circulando na rua eles levavam. Se a gente tivesse dentro de casa e eles soubessem que tinha travesti morando lá eles invadiam e levava. Uma vez na morte da finada Clara Nunes eu sai para comprar um quilo de acém no açougue ali na outra rua e quando eu voltava com a carne a polícia pegou e me levou com a carne e com tudo. Eram dez e meia da manhã, me levou pra delegacia. Você está me prendendo por que? porque vim comprar uma carne? Não, porque você é travesti, tem peito. Bora! (Sá, 2015).

O acontecimento da morte da cantora Clara Nunes marca na memória de Marta a data exata desse encarceramento. Era 2 de abril de 1983, alguns anos antes da Operação Tarântula ser anunciada e um contexto ainda um pouco distante dos referenciais de uma redemocratização mais efetiva. Contudo chama atenção para dois pontos, se por um lado a abordagem é mais explícita e o motivo não precisa sequer ser justificado para além do fato de ela ser travesti, por outro o delegado responsável pela operação de 1987 fala em evitar a prática do trottoir. De um modo ambíguo, a palavra francesa fala tanto da prática de prostituição de rua e abordagem de possíveis clientes enquanto se caminha, quanto do próprio fato de se caminhar pela calçada. Marta Sá poderia facilmente ter sido acusada dessa prática, enquanto ela registra o absurdo da abordagem ao marcar que eram dez e meia da manhã e que ela voltava com um quilo de carne do açougue próximo da sua casa.

$\mathrm{Na}$ entrevista não se comenta detalhes do processo de incriminação de Marta nesse momento em que fora detida, mas entendendo o contexto sob as lentes que nos apontam possíveis processos inquisitoriais, podemos perceber que a tipificação formal de sua transgressão é secundária, pois tal como as 56 travestis detidas apenas na primeira noite de Operação Tarântula, aciona-se aqui o direito penal do autor que ao mesmo tempo é também o direito penal do inimigo.

\section{Entre fascismos e vontades de punir - o encarceramento enquanto ferramenta necropolítica}

Diante do conjunto de digressões que ganham forma até esse ponto da presente discussão, as propostas de Achille Mbembe novamente nos são úteis, na medida em que nos ajudam a entender redes de poder que creditam a alguns o direito de matar. No ensaio Necropolítica, o autor analisa como as dinâmicas de terror e guerra passam a ser políticas cotidianas em contextos de colonização e, para tal, a definição de políticas de inimizade torna-se elemento central que toma na aniquilação do outro o próprio exercício da soberania. Assim, segundo ele, "a colônia representa o lugar em que a soberania consiste fundamentalmente no exercício de um poder à margem da lei (ab legibus solutus) e no qual tipicamente a 'paz' assume a face de uma 'guerra sem fim'” (Mbembe, 2016, p. 132). Para que se componha um estatuto de guerra constante, se faz necessária a eleição cotidiana de inimigos. A relação do Estado enquanto agente do terror pode ser entendido como tentativas de estabelecimento de ordem e moralidade, elementos historicamente vistos como impossíveis em contextos das colônias, posto que no sistema de racionalização europeu, o modelo de dominação se justificaria pela retificação da colônia como primitiva, selvagem e incapaz de ordenação estatal por si própria.

Em suma, as colônias são zonas em que guerra e desordem, figuras internas e externas da política, ficam lado a lado ou se alternam. Como tal, as colônias são o local por excelência em que os controles e as garantias de ordem judicial podem ser suspensos - a zona em que a violência do estado de exceção supostamente opera a serviço da "civilização" (Mbembe, 2016, p. 133).

Embora no contexto brasileiro de 1987 as dinâmicas da relação imperialista entre nós e os países do "primeiro mundo" não sejam tão explícitas como o 
eram um século antes, ainda é possível perceber o discurso civilizatório como motivador da suspensão de um estado de direitos para alguns sujeitos. Em nome dos "bons costumes" opera-se o encarceramento de travestis, como lembra Marta Sá. Se voltarmos à fórmula que relaciona corpos travestis com delito, podemos entender que tais corpos são atravessados por um processo de criminalização que produz um corpo em potencial a ser encarcerado. Davis e Dent (2011) comentam que a instituição da prisão e seu uso produzem a tipificação de um prisioneiro que em uma lógica que se retroalimenta, justifica a existência e a expansão da prisão. Tal tipificação, em diálogo com Mbembe, pode ser pensada como a produção de inimigos internos do Estado que se proliferam nas zonas periféricas, justificando ao poder soberano o estatuto de "guerra sem fim". Na operacionalização do necropoder, os corpos que não foram ainda exterminados precisam ser marcados e contidos. Aqui a prisão surge como paradigma central do modelo punitivista (Davis, \& Dent, 2011).

Para pensar sobre o modelo de tipificação e produção do "detento", nos ajuda recordar Fanon quando no livro Os Condenados da Terra traduz a violência como central para o estabelecimento do projeto colonial europeu. Em um mundo de dominação de uns por outros, marcar as fronteiras é parte fundamental da estratégia. Assim:

O mundo colonial é um mundo maniqueísta. Não basta ao colono limitar fisicamente, com o auxílio de sua polícia e de sua gendarmaria, o espaço do colonizado. Como que para ilustrar o caráter totalitário da exploração colonial, o colono faz do colonizado uma espécie de quintessência do mal (Fanon, 1968, p. 30).

Fala-se aqui do mesmo processo que Davis e Mbembe apontam. A delimitação do mal na figura do colonizado justifica as mais diversas intervenções, inclusive o genocídio, o extermínio e a necessidade constante do aprimoramento das práticas punitivas legais. A um ser que representa a própria quintessência do mal, não se fazem necessários o direito penal do fato ou mesmo o modelo acusatório do sistema processual penal. Assim como nas cruzadas religiosas de combate ao mal, a lógica inquisitorial atualizada em proposições como as da criminologia positivista já demarca muito objetivamente quais corpos e subjeti- vidades são os inimigos, bem como estabelece formas rápidas e eficazes de neutralização.

Ao pensar sobre um traçado histórico que perpassa a existência das prisões enquanto dispositivo do Estado, Reishoffer e Bicalho (2015) comentam sobre como a centralização da prisão enquanto paradigma da segurança pública provém de um modo de entender a relação entre sociedade e transgressão que se pauta na manutenção de uma suposta dicotomia maniqueísta. Junta-se a isso a proliferação de uma série de discursos de especialistas que buscam encontrar no sujeito as raízes do mal, associando classes perigosas e tipos padrões de pessoas criminosas às classes populares, em um constante controle dos pobres e mesmo a neutralização daqueles que desequilibram o cotidiano dos cidadãos plenos (Reishoffer, \& Bicalho, 2015).

Pensar necropolítica implica em perceber formas de organização do Estado pautados na dinâmica da exceção (Mbembe, 2016). Campos de fronteiras borradas são cenário para o exercício calculado da violência que se torna cotidiana. Cabe pensar a prisão como um desses espaços de fronteira (Davis, \& Dent, 2011) em que a suspensão do estado de direitos opera em favor do combate ao mal ali encarcerado. Trata-se, pois, de uma continuação do processo que anteriormente elegeu esse mal para em seguida justificar que sua vida sempre ocorra nestes tais espaços de fronteiras borradas. Para Fanon, no mundo colonial a infraestrutura econômica é também uma superestrutura que o permite elaborar o enunciado de que "o indivíduo é rico porque é branco e é branco porque é rico" (Fanon, 1968, p. 29). Atualizando esse enunciado, Marta Sá aprendeu com sua experiência de que no Brasil dos anos 1980, você é detida pela polícia porque é travesti e, paradoxalmente, você é travesti ao ser assim nomeada pela polícia.

\section{Concluindo: os perversos filhotes da aranha}

No decorrer desse texto aponta-se uma certa racionalidade punitivista que se soma ao pânico moral produzido pela divulgação do que foi nomeado como epidemia de AIDS no fim dos anos 1980, materializando formas de perseguição e mesmo caça às travestis e demais população LGBTI brasileira. Desse modo, em São Paulo, a criação de uma operação policial e sua divulgação na mídia local apontam para um movimento que é ao mesmo tempo localizado e 
generalizado por outros territórios. Suspeita-se aqui que em todos os estados brasileiros facilmente nos deparamos com relatos de travestis que viveram nessa época, sobre as violências legitimadas pelo Estado, bem como sobre a arbitrariedade de processos de incriminação a que foram submetidas. Contudo, nos potencializa a reflexão entender que as ações advindas das lógicas punitivistas são sempre originadas em uma trama de acontecimentos antecedentes que desvela as linhas de poder ali presentes.

Em matéria publicada no dia 17 de janeiro de 2018, também na Folha de São Paulo (Canofre, \& Pereira, 2018), é relembrada a Operação Tarântula ocorrida 31 anos antes, a partir da trajetória de Patrícia, uma das travestis presas na ocasião. A matéria relata ainda que a operação, que se iniciou no dia 27 de fevereiro de 1987, foi oficialmente suspensa no dia 10 de março do mesmo ano após grupos de defesa dos direitos LGBTI começarem a pressionar a Secretaria de Segurança Pública de São Paulo. Estima-se que nos poucos dias em vigência, a operação chegou a prender mais de 300 travestis.

Apesar da curta vida, a tarântula aqui apontada foi extremamente eficaz e produtiva e, ainda que não mais anunciada em seu nome, nos cabe desconfiar que suas teias continuaram enredando travestis em processos de incriminação operados por seletividade penal e extermínio mesmo muito depois. Neste ponto, cabe recordar a denúncia feita pelo coletivo Arouchianas de perseguição policial a travestis que se prostituem na Praça da República e na região do Arouche, na cidade de São Paulo. Segundo registro em vídeo da Carta Capital, no dia 5 de outubro de 2017, nove travestis foram conduzidas a $3^{\circ}$ distrito policial (DP) acusadas de "prostituição" e, ao chegarem na delegacia de polícia, a acusação muda para desacato. No dia seguinte à detenção, o coletivo Arouchianas organiza uma manifestação na Praça da República para denunciar esse fato. Chama a atenção a fala de Nicolle Mahier, tanto durante o protesto quanto em entrevista para a Carta Capital, ao trazer que:

Não é porque sou prostituta que não tenho direitos humanos; não é porque sou prostituta que eu sou obrigada a sofrer opressão da polícia; não é porque sou prostituta que não pago impostos, não pago tributos, não pago taxas enquanto uma cidadã brasileira e eu mereço respeito. [...] O fato do sargento bigode não é um fato isolado, se analisarmos vários policiais militares e civis mais antigos, eles tem essa visão mesmo de que travesti é marginal, de que travesti é um sujeito que pode trazer um risco a sociedade e é muito engraçado isso porque aonde que minha construção corporal é um risco para a sociedade? (Carta Capital, 2017).

As travestis manifestantes na Praça da República marcam que a lógica que atravessa as abordagens é o fomento da velha política da inimizade (Mbembe, 2016) dirigida aos corpos trans nas vias públicas. Se o inferno são sempre os outros, como afirma a máxima exaustivamente repetida, a construção coletiva de monstruosidades se compõe numa curiosa ambivalência. Se eles (os outros) são monstros, as pessoas de bem são autorizadas a cometer atrocidades diversas em sua própria defesa. A abjeção enquanto eleição de monstruosidades a serem combatidas falam aqui muito mais sobre os deslocamentos que os corpos eleitos para ocupar esse lugar causam do que sobre relações ontologicamente estabelecidas. Cohen (2000) fala sobre como a configuração desse estranho personagem sempre aponta para as fendas que sua existência necessariamente causa nas normalidades. Desse modo:

Um constructo e uma projeção, o monstro existe apenas para ser lido: o monstrum é, etimologicamente, "aquele que revela", "aquele que adverte", um glifo em busca de um hierofante. Como uma letra na página, o monstro significa algo diferente dele: é sempre um deslocamento; ele habita, sempre, o intervalo entre o momento da convulsão que o criou e o momento no qual ele é recebido - para nascer outra vez (Cohen, 2000, p. 27).

Lança-se a pergunta retórica sobre quais perigos a construção corporal não cisgênera traz para a sociedade e Cohen nos ajuda aqui a delimitar suspeitas. Se o mostro é aquele que ameaça ao revelar, o principal perigo que o corpo trans representa nessa perspectiva é o fato de revelar o caráter artesanal da construção de todos os corpos (inclusive os não trans), bem como a artificialidade que sustenta suas fronteiras e que pode facilmente ser borrada. Essa revelação pode nos ser uma pista sobre o processo de construção coletiva da abjeção.

Sendo um elemento que atravessa a nossa cultura, a ojeriza aos corpos trans pode ser percebida 
como um dos elementos constitutivos da subjetividade da população brasileira. Assim sendo, diante de dinâmicas inquisitoriais em processos penais, a reprodução de pressuposições perversas que acionam (ainda que sutilmente) o direito penal do inimigo são sempre uma possibilidade na relação da justiça criminal com travestis.

Em 12 de abril de 2015, Veronica Bolina, negra, prostituta, travesti, foi detida sob acusação de ter entrado em conflito com uma vizinha. Soma-se a acusação de ter mordido a orelha de um agente carcerário quando estava sendo transferida de cela no $2^{\circ}$ DP no bairro do Retiro, em São Paulo. Porém, o caso de Veronica repercutiu na época a partir de imagens feitas dentro das dependências policiais e amplamente veiculadas em redes sociais nas quais ela aparece ao chão, cercada por vários agentes de segurança pública, nua, amordaçada com os longos cabelos raspados, o rosto completamente desfigurado e visíveis sinais de tortura. A exposição exaustiva da imagem gerou comoção a partir da hashtag \#SomosTodasVeronica. Apesar de toda a comoção causada, Veronica foi encaminhada para o centro de detenção provisória de Pinheiros, onde ela passou três meses na solitária e mais nove numa cela específica para a população travesti da unidade. Após esse tempo, ela passou sete meses na ala psiquiátrica do presídio de Taubaté. Em entrevista para o Brasil de Fato publicada em 29 de janeiro de 2018, a própria Veronica comenta sobre a noite em que fora submetida a uma série de torturas (Pina, 2018).

Não se coloca aqui em análise o caráter moral de presunção ou não de inocência. Mas chama-se atenção para os níveis absurdos de violência com que o processo de incriminação de Veronica é recebido na delegacia. Na entrevista para o Brasil de Fato, além de ter os cabelos cortados e as roupas rasgadas, ela refere a socos, chutes, tentativas de asfixia com saco plástico, uso de spray de pimenta diretamente em seus olhos, humilhações variadas que incluíam agentes pisotearem seu rosto e ainda traz ter sido estuprada com um cabo de vassoura. Passada a tortura, Veronica foi encaminhada ao hospital Mandaqui e diz que também lá houve humilhações. "Alguns estavam com dó, mas a maioria me xingava e dizia 'não vou botar a mão nisso porque isso deve estar doente"” (Pina, 2018). A forma com que parte da equipe do hospital se refere a ela como "isso" aponta para uma desumanização que impossibilita qualquer ato de empatia.
O fato de o Brasil seguir sendo líder no ranking de assassinatos brutais de pessoas trans nos convida a pensar sobre como o fascismo enquanto impossibilidade de copertencimento (Mbembe, 2014) opera no ódio cotidiano a diferença. Arendt (1999) nos ajuda aqui a atentarmos para a sutileza dos processos de banalização da violência e do extermínio. Seguindo sua linha de pensamento, é ineficaz responsabilizarmos pessoas ou grupos específicos pelos altos índices de assassinatos enquanto não assumirmos que há como base todo um sistema de permissividades que opera de modo a desumanizar as pessoas trans e como consequência tornar banais as violências cometidas contra este segmento. O mal (aqui entendido como genocídio, extermínio e aniquilação violenta) se possibilita a partir de um conjunto de desresponsabilizações coletivas. A Operação Tarântula certamente foi um acontecimento emblemático na banalização do mal transfóbico, porque nos permite visualizar como uma certa racionalidade pode ser suficiente para mobilizar políticas de segurança pública marcadas por processos de criminalização, incriminação e encarceramento. Contudo, este não é um acontecimento isolado; enquanto suas raízes despontam temporalidades complexas, os longos braços da tarântula permanecem vivos ainda hoje, o que nos convida a atentar para os elementos que, explícitos ou não, acionam para travestis modos de funcionamento do direito penal pautados completamente nas políticas da inimizade (Mbembe, 2016).

Se a justiça pode ser entendida como constantemente produzida a partir da relação entre pessoas, instituições e normas, a fala de Zé Celso ao comentar o assassinato de seu irmão no documentário Temporada de Caça nos aponta uma possível pista.

Eu não acredito em justiça vinda de administração ou burocracia. Pra mim a justiça é uma invenção cultural. Então quando morre um poeta como Luiz Antônio e quando ele morre com cento e tantas facadas, a desproporção que existe no acontecimento desperta um tipo de clamor e tem que despertar um tipo de ação em que você tem que novamente reinventar a justiça (Moreira, 1988).

Reinventar a justiça é necessariamente propor outros modos de intervenção para os operadores da segurança, historicamente atravessada por proces- 
sos estruturais de composição de desigualdades no contexto brasileiro. Como ferramenta, podemos nos apoiar na leitura de Khaled Junior $(2013 ; 2016)$ para atentarmos que perceber as formas como a busca da verdade é operacionalizada nos empresta indícios objetivos para discutir sobre a disseminação de ódio e do punitivismo como estratégia de gestão da segurança pública e da justiça criminal em nosso país.

\section{Referências}

Arendt, H. (1999). Eichmann em Jerusalém: Um relato sobre a banalidade do mal. São Paulo: Companhia das Letras.

Barata, G. F. (2006). A primeira década da aids no Brasil: O Fantástico apresenta a doença ao público (1983-1992 (dissertação de mestrado). Departamento de História, Universidade de São Paulo, São Paulo, SP, Brasil.

Bicalho, P. P. G. (2013). Ditadura e democracia: qual o papel da violência de Estado? In: Conselho Regional de Psicologia do Rio Grande do Sul (Org.), Entre garantia de direitos e práticas libertárias (pp. 13-34). Porto Alegre, RS: o autor.

Canofre, F, \& Pereira, C. (2018). Sobrevivi. Folha de São Paulo. Recuperado de https:/ /wwwl.folha.uol.com.br/cotidiano/2018/01/1951067-sobrevivi-diz-vitima-de-operacao-da-policia-de-caca-a-travestis-ha-31-anos.shtml

Carta Capital (2017). Travestis relatam perseguição de policiais no Centro de São Paulo. Recuperado de https:// www.youtube.com/watch?v=plw3dmqzhZA

Castro, E. (2009) Vocabulário de Foucault: Um percurso pelos seus temas, conceitos e autores. Belo Horizonte, MG: Autêntica.

Chauí, M., \& Nogueira, M. A. (2007) O pensamento político e a redemocratização do Brasil. Lua Nova, (71), 173-228. https:// doi.org/10.1590/S0102-64452007000200006

Cohen, J. J. (2000) A cultura dos monstros: sete teses. In: T. T. Silva (Org.), Pedagogia dos monstros (pp.23-60). Belo Horizonte, MG: Autêntica.

Davis, A., \& Dent, G. (2011). A prisão como fronteira: Uma conversa sobre gênero, globalização e punição. Revista Estudos Feministas, 11(2), 523-531. https:// doi.org/10.1590/S0104-026X2003000200011

Decreto-Lei No 2.848, de 7 de dezembro de 1940. Código Penal. Diário Oficial da União, 31 dez. 1940

Elbert, C. A. (2003) Manual básico de criminologia. Porto Alegre, RS: Ricardo Lenz.

Fanon, F. (1968) Os condenados da terra. Rio de Janeiro, RJ: Civilização Brasileira.

Galvão, J. (2002). 1980-2001: Uma cronologia da epidemia de HIVIAIDS no Brasil e no mundo. Rio de Janeiro, RJ: ABIA.

Guel, A. (2017). Alice no país que mais mata travestis. Recuperado de https://www.youtube.com/watch?v=T9KV8gLkihE

Góes, L. (2015). A "Tradução" do paradigma etiológico de criminologia no Brasil: Um diálogo entre Cesare Lombroso e Nina Rodrigues da Perspectiva Centro-Margem (dissertação de mestrado). Faculdade de Direito, Universidade Federal de Santa Catarina, Florianópolis, SC, Brasil.

Haraway, D. (2016). Tentacular thinking: anthropocene, capitalocene, chthulucene. Recuperado de https://www.e-flux.com/journal/75/67125/tentacular-thinking-anthropocene- capitalocene-chthulucene/

Khaled Junior, S. H. (2013). A busca da verdade no processo penal: Para além da ambição inquisitorial. São Paulo, SP: Atlas.

Khaled Junior, S. H. (2016). Discurso de ódio e sistema penal. São Paulo, SP: Letramento.

Kristeva, J, (1989). Poderes del horror. Cidade do México: FCE.

Mbembe, A. (2014). Crítica da razão negra. Lisboa: Antígona.

Mbembe, A. (2016). Necropolítica. Arte \& Ensaios, 32, 123-151.

Misse, M. (1999). Malandros, marginais e vagabundos: A acumulação social da violência no Rio de Janeiro (tese de doutorado). Instituto Universitário do Rio de Janeiro, Rio de Janeiro, RJ, Brasil. 
Psicologia: Ciência e Profissão 2018 v. 38 (núm. esp.2), 175-191.

Moreira, R. (1988). Hunting season/Temporade de caça. Recuperado dehttps:/ /www.youtube.com/watch?v=rjan_Yd0C5g

Pina, R. (2018). Verônica Bolina: "Estou recomeçando, reconstruindo minha vida". Brasil de Fato. Recuperado de https://www.brasildefato.com.br/especiais/veronica-bolina-estou-recomecando-reconstruindo-minha-vida/

Polícia Civil "combate' a Aids prendendo travestis. (1987). Folha de SP Recuperado de https://acervo.folha.com. br /leitor.do?numero=9793\&keyword=Tarântula\&anchor=4104113\&origem=busca\&pd=ef05d4e9c5760ee525b$552 \mathrm{f} 38274 \mathrm{c5c} 8$

Reishoffer, J. C., \& Bicalho, P. P. G. (2015) A circunscrição histórica das prisões e a crítica criminológica. In: F. Farias, \& L. Faceira (Orgs.), Punição e prisão: Ensaios críticos (pp. 13-26). Rio de Janeiro, RJ: Lumen Juris.

Reishoffer, J. C., \& Bicalho, P. P. G. (2009). Insegurança e produção de subjetividade no Brasil contemporâneo. Fractal: Revista de Psicologia, 21(2), 425-444. https://doi.org/10.1590/S1984-02922009000200015

Rodrigues, N. (1899). Mestiçagem, degenerescência e crime. Archives d'Anthropologie Criminelle, 83(14), 112-134.

Rodriguez, C. (2016). Las travestis debemos tener derecho a leer sobre lo que escriban otras travestis. Recuperado de http://www.claudiarodriguez.cl/las-travestis-debemos-derecho-leer-lo-escriban-otras-travestis/

Rubin, G. (2003). Pensando sobre sexo: Notas para uma teoria radical da política da sexualidade.Cadernos Pagu, (21), 1-88.

Rufino, L. (2015). Exu e a pedagogia das encruzilhadas: Sobre conhecimentos, educações e pós-colonialismo. Anais do Seminário Internacional As Redes Educativas e as Tecnologias: Movimentos Sociais e Educação, Rio de Janeiro, RJ, Brasil, 8.

Sá, M. (2015). Travesti fala sobre a repressão da ditadura militar. A Tarde TV. Recuperado de https://www.youtube. com/watch?v=VEWp4yl3j5Q

Salvadori, F. (2014). Coração destroçado. Inarrável. Recuperado de https://inarravel.files.wordpress.com/2014/09/ ze-celso.pdf

Terto Junior, V. (2002). Homossexualidade e saúde: Desafios para a terceira década de epidemia de Hiv/AIDS. Horizontes Antropológicos, 8(17), 147-158. https://doi.org/10.1590/S0104-71832002000100008

\section{Céu Cavalcanti}

Psicóloga, mestre em Psicologia, discente do curso de Doutorado em Psicologia da Universidade Federal do Rio de Janeiro (UFRJ), Rio de Janeiro - RJ. Brasil. Bolsista CNPq.

E-mail: ceucavalcanti@gmail.com

(iD https://orcid.org/0000-0001-9007-1600

\section{Roberta Brasilino Barbosa}

Psicóloga, especialista em Psicologia Jurídica, mestre e doutora em Psicologia. Pesquisadora de Pós-doutorado no Programa de Pós-graduação em Psicologia da Universidade Federal do Rio de Janeiro (UFRJ), Rio de Janeiro - RJ. Brasil. E-mail: robertabrasilino@gmail.com

(iD) https://orcid.org/0000-0003-0943-916X

\section{Pedro Paulo Gastalho Bicalho}

Psicólogo, especialista em Psicologia Jurídica, mestre e doutor em Psicologia. Professor Associado do Instituto de Psicologia da Universidade Federal do Rio de Janeiro, vinculado ao Programa de Pós-graduação em Psicologia e ao Programa de Pós-graduação em Políticas Públicas em Direitos Humanos. (UFRJ), Rio de Janeiro - RJ. Brasil. Bolsista de produtividade em pesquisa (CNPq).

E-mail: ppbicalho@ufrj.br

Endereço para envio de correspondência:

Programa de Pós-graduação em Psicologia da Universidade Federal do Rio de Janeiro Av. Pasteur, 250, pavilhão Nilton Campos, Urca, Rio de Janeiro-RJ

22290-902 
Recebido 16/08/2018

Aprovado 23/08/2018

Received 08/16/2018

Approved $08 / 23 / 2018$

Recibido 16/08/2018

Aceptado 23/08/2018

Como citar: Cavalcanti, C., Barbosa, R.B. \& Bicalho, P.P.G. (2018). Os Tentáculos da Tarântula: Abjeção e necropolítica em operações policiais a travestis no Brasil pós-redemocratização. Psicologia: Ciência e Profissão, 38(n.spe.2), 175-191. https://doi.org/10.1590/1982-3703000212043

How to cite: Cavalcanti, C., Barbosa, R.B. \& Bicalho, P.P.G. (2018). The Tarantula Tentacles: Abjection and necropolitics in police operations to trans women in post-redemocratized Brazil. Psicologia: Ciência e Profissão, 38(n.spe.2), 175-191. https://doi.org/10.1590/1982-3703000212043

Cómo citar: Cavalcanti, C., Barbosa, R.B. \& Bicalho, P.P.G. (2018). Los Tentáculos de la Tarántula: Abyección y necropolítica en operaciones policiales a travestis en Brasil post-redemocratización. Psicologia: Ciência e Profissão, 38(n.spe.2), 175-191. https://doi.org/10.1590/1982-3703000212043 